\title{
The Effect of Aluminum Source on Performance of Beta- Zeolite as a Support for Hydrocracking Catalyst
}

\author{
M. Hadi, H.R. Aghabozorg*, H.R. Bozorgzadeh, M.R. Ghasemi \\ Catalysis Research Division, Research Institute of Petroleum Industry (RIPI), Tehran, Iran
}

Received: 25 $5^{\text {th }}$ April 2018; Revised: 22 $2^{\text {nd }}$ July 2018; Accepted: $29^{\text {th }}$ July 2018; Available online: $14^{\text {th }}$ November 2018; Published regularly: December 2018

Abstract

In this paper, three different kinds of aluminum sources (sodium aluminate, aluminum sulfate and aluminum isopropylate) were used for preparing of nano beta-zeolite. The as synthesized zeolites were mixed with the as prepared amorphous silica-alumina to produce the supports for hydrocracking catalyst. The prepared supports were used for preparation of NiMo/silica alumina-nano beta-zeolite by impregnation method. The influence of the aluminum source for preparation of beta-zeolite on the performance of the prepared catalysts has been studied. The samples were thoroughly characterized by XRay diffraction method (XRD), field emission-scanning electron microscopy (FE-SEM), $\mathrm{N}_{2}$ adsorptiondesorption isotherms (BET), temperature programmed desorption (TPD) and temperature programmed reduction (TPR) methods. The catalysts performance was evaluated by vacuum gas oil (VGO) hydrocracking at $390{ }^{\circ} \mathrm{C}$ in a fixed bed reactor. The XRD patterns showed that the beta-zeolite samples obtained from the present methods were pure and highly crystalline and the crystal size of the prepared zeolites were in nanometer scale. Crystallite size of nano beta-zeolite synthesized by aluminum isopropylate $\left[\mathrm{Al}(\mathrm{iPrO})_{3}\right]$ was smaller than those of prepared by the other aluminum sources. The catalyst containing this zeolite with higher surface area $\left(231 \mathrm{~m}^{2} / \mathrm{g}\right)$ and more available acid sites (1.66 mmol NH$/ \mathrm{g}$ ) possessed higher activity and selectivity to gas oil (71.9 \%). Copyright (C) 2018 BCREC Group. All rights reserved

Keywords: Hydrocracking; Nano Beta-Zeolite; Aluminum Isopropylate; Aluminum Sources

How to Cite: Hadi, M., Aghabozorg, H.R., Bozorgzadeh, H.R., Ghasemi, M.R. (2018). The Effect of Aluminum Source on Performance of Beta-Zeolite as a Support for Hydrocracking Catalyst. Bulletin of Chemical Reaction Engineering \& Catalysis, 13 (3): 543-552 (doi:10.9767/bcrec.13.3.2570.543-552)

Permalink/DOI: https://doi.org/10.9767/bcrec.13.3.2570.543-552

\section{Introduction}

Hydrocracking process will play an important role in the modern petrochemical process. One of the most important typical of hydrocracking is its ability to change a wide range of feedstock to a kind of products. Hydrocracking catalysts are dual-function catalysts, having both hydrogenation and cracking function. Cracking function is controlled by the acid-

* Corresponding Author.

E-mail: aghabozorghr@ripi.ir (H.R. Aghabozorg) ic support, while the hydrogenation function is provided by metals dispersed on the support [1]. It is reported that, more weak and medium acidic sites can increase the selectivity of middle distillates.

Amorphous silica-alumina has medium acidic site which makes higher selectivity to middle distillates [7-8]. On the other hand, zeolites with strong acid site are widely used in petroleum refining, petrochemistry, fine chemicals production, and environmental catalysis. In spite of its long background, zeolite catalysis is 
still an active research field, with the contributions of the various properties of the zeolite microporous crystals to catalysis performance. One of the most important of zeolite characteristics is crystal size, which influences the external surface area and the mesoporosity. Reducing the crystal size in the nanoscale range $(<100 \mathrm{~nm})$ makes considerable differs in the physicochemical properties of the zeolite, especially in the external surface area, the micropore volume, and the fraction of acid sites dispersed on the external surface of the crystals [2]. Y-zeolite is used as a part of the hydrocracking catalyst, because of its high acid strength, controlled density of acid sites, high hydrogen-transfer ability, and superior performance in the hydrocracking process compared to other supports [3-5]. Beta-zeolite with large pore has also shown as a part of hydrocracking catalysts [6], but zeolite has a high selectivity to gases that cause restricting the commercial application of this compound. On the other hand, zeolite with high acid strength has higher activity of catalyst but lower selectivity of gas oil.

The synthesis of nano beta-zeolite materials has been approached by several methods. A detailed study of the synthesis of beta-zeolite using tetraethylorthosilicate as a source of silicon has been reported [9]. The feasibility of synthesizing beta-zeolite using fume silica, silica sol and silica gel as a source of silica has been reported in literature [10-13]. The influence of the acid site density and crystal size on catalytic behavior of this compound has also been studied by preparing two nanocrystalline betazeolites with different $\mathrm{Si} / \mathrm{Al}$ ratio and by comparing the catalytic performance of these compounds with that of the beta-zeolite with large crystals [13]. However, a detailed study of comparing the properties of nano beta-zeolite with different source of aluminum has not been published so far.

In this paper, we have studied the effect of aluminum sources on the beta-zeolite properties by appraising catalytic function of NiMocatalysts based on beta-zeolite for the mild hydrocracking of vacuum gas oil (VGO) at mild pressure of $5.5 \mathrm{MPa}$, and $390{ }^{\circ} \mathrm{C}$. The influences of beta-zeolite crystallite size on acidity, physical properties of catalysts (surface area, pore volume and pore diameter) and metal species reduction on the catalyst have also been studied.

\section{Materials and Methods}

\subsection{Support Preparation}

Tetraethylammonium hydroxide TEAOH (Aldrich, $20 \%$ by weight solution), Ludox colloidal silica (Aldrich, $40 \%$ suspension in water), aluminum sulfate hexadecahydrate (Fluka, $99 \%$ ), aluminum isopropylate (Sigma, $99 \%$ ), $\mathrm{NaOH}$ (Merck, $99 \%$ ) and Aluminum hydroxide (Merck, $99 \%$ ) were used for the synthesis of nano beta-zeolites.

Three samples of as synthesized beta-zeolite were prepared in the form of colloidal solutions. The first sample, with a particle size of $<50 \mathrm{~nm}$ indicated as B1, was prepared by mixing a solution of $\mathrm{NaAlO}_{2}$ in aqueous tetraethylammonium hydroxide with an aqueous colloidal suspension of silica at room temperature, followed by stirring for $4 \mathrm{~h}$. The composition of the crystallization solution for the $\mathrm{B} 1$ zeolite was $60 \mathrm{SiO}_{2}: 3 \mathrm{Na}_{2} \mathrm{O}: \mathrm{Al}_{2} \mathrm{O}_{3}: 5$ (TEA) ${ }_{2} \mathrm{O}: 1500$ $\mathrm{H}_{2} \mathrm{O}$. The gel was aged at room temperature overnight. The sodium aluminate (43.8 wt.\% $\mathrm{Al}_{2} \mathrm{O}_{3}, 39$ wt.\% $\mathrm{Na}_{2} \mathrm{O}$ and 17.2 wt.\% $\mathrm{H}_{2} \mathrm{O}$ ) has been prepared by reacting stoichiometric amounts of aluminum hydroxide and sodium hydroxide in slurry, followed by evaporation at $100^{\circ} \mathrm{C}$. The second sample, with a particle size of $<30 \mathrm{~nm}$, designated as B2, was prepared by clear solution containing aluminum sulfate hexadecahydrate as a source of aluminum and silica sol in specific amount of $\mathrm{NaOH}$. This mixture was added to tetraethylammonium hydroxide. The composition of the crystallization solution for the $\mathrm{B} 2$ sample was $\mathrm{SiO}_{2}$ : 0.154 $\mathrm{Na}_{2} \mathrm{O}: 0.02 \mathrm{Al}_{2} \mathrm{O}_{3}$ : 6.29 TEAOH. The third sample, with a particle size of $<10 \mathrm{~nm}$, named as B3, was prepared by aluminum isopropylate as a source of aluminum and silica sol in aqueous tetraethylammonium hydroxide at room temperature. The molar composition of the gel was $25 \mathrm{SiO}_{2}: 0.25 \mathrm{Al}_{2} \mathrm{O}_{3}: 9$ TEAOH: $295 \mathrm{H}_{2} \mathrm{O}$.

All of these samples were encountered to hydrothermal treatment of nucleated gel carrying out in a teflon lined stainless steel autoclave, in a static condition at $140{ }^{\circ} \mathrm{C}$ for 6 days. The crystalline materials were purified in three steps consisting of high-speed centrifugation at $6000 \mathrm{rpm}$ for $30 \mathrm{~min}$, removal of the mother liquor, and redispersion in de-ionized water. The resulting solid product was washed with de-ionized water until the $\mathrm{pH}<9$ were observed. The wet solids were dried at $110^{\circ} \mathrm{C}$ for $4 \mathrm{~h}$ and calcined at $550{ }^{\circ} \mathrm{C}$ for $4 \mathrm{~h}$ in the presence of air.

Amorphous silica-alumina (ASA) was prepared using the method of sequential precipitation according to the technique described else- 
where [14]. First, aluminum hydroxide was precipitated by mixing aluminum sulfate solution and aqueous ammonia solution at $60^{\circ} \mathrm{C}$ in $\mathrm{pH}$ of 8.0 under vigorous stirring. Aqueous solution of sodium silicate was added to the obtained suspension at the same temperature and $\mathrm{pH}$. The product was recovered by filtration and washed with water until $\mathrm{SO}_{4}{ }^{2-}$ was not detected in washing water. The prepared filter cake was spray-dried, then dried at $120^{\circ} \mathrm{C}$ for $4 \mathrm{~h}$ and finally calcined at $700{ }^{\circ} \mathrm{C}$ for $4 \mathrm{~h}$ in air.

The above hydrothermally treated betazeolite (10 wt.\%) and amorphous silica-alumina (60 wt.\%) were mixed with a binder (partially acid-peptized alumina, SASOL, SB-1), and the obtained paste was extruded. The extruded sample was left at room temperature for a few hours and then placed in an oven at $110{ }^{\circ} \mathrm{C}$ for $4 \mathrm{~h}$. The dried sample was finally calcined at $550{ }^{\circ} \mathrm{C}$ for $4 \mathrm{~h}$, ready for metal impregnation.

\subsection{Catalyst Preparation}

Ni-Mo catalysts were prepared via coimpregnation method with aqueous solution of the proper amounts of nickel nitrate hexahydrate $(1.00 \mathrm{~g})$ and ammonium heptamolybdate $(1.14 \mathrm{~g})$, the impregnated support dried at 110 ${ }^{\circ} \mathrm{C}$ for $4 \mathrm{~h}$, followed by calcination at $550{ }^{\circ} \mathrm{C}$ for $4 \mathrm{~h}$. The total concentration of $\mathrm{Ni}$ in the catalyst was $5 \mathrm{wt} . \%$, and the total concentration of Mo in the catalyst was 15 wt.\%.

\subsection{Catalytic Characterization}

The crystallinity of the samples was determined X-ray diffraction (XRD) via PW1840 using CuKa radiation. Crystal diameter of the prepared samples was calculated according to Scherrer equation. Field emission-scanning electron microscopy (FE-SEM) images were taken by Mira3-XMU FE-SEM. BrunauerEmmett-Teller (BET) surface area, pore size and pore volume measurements of the catalysts were determined from physical adsorption of $\mathrm{N}_{2}$ using liquid nitrogen at $77 \mathrm{~K}$ by an

Table 1. Vacuum gas oil feedstock properties

\begin{tabular}{llc}
\hline & \multicolumn{1}{c}{ Properties } & Values \\
\hline & Density $\left(20^{\circ} \mathrm{C}\right)\left(\mathrm{g} \mathrm{cm}^{-3}\right)$ & 0.876 \\
\hline SIMDIST & Gas $(<90) \%$ & 0 \\
distillation & Naphtha $(90-160) \%$ & 0 \\
Fraction & Kerosene $(160-275) \%$ & 0.2 \\
$\left({ }^{\circ} \mathrm{C}\right)$ & Gas Oil $(275-377) \%$ & 9.9 \\
& Vacuum Gas Oil $(377-$ & 89.9 \\
& $518) \%$ \\
\hline
\end{tabular}

ASAP2420 Micromeritics adsorption analyzer. The acidic properties of the Ni-Mo/beta-zeolites catalysts were determined by AutoChem 2900 (Micromeritics) temperature-programmed desorption (TPD) of ammonia. The reducibility of the supported $\mathrm{Ni}$ and Mo metal oxides in the fresh catalysts was studied by temperatureprogrammed reduction (TPR) using an AutoChem 2900 (Micromeritics).

\subsection{Catalytic Activity Evaluation}

Hydrocracking of vacuum gas oil feedstock was appraised in a fixed-bed continuous reactor loaded with $5 \mathrm{~g}$ of catalyst. The vacuum gas oil feedstock properties are shown in Table 1. The schematic diagram of experimental setup for hydrocarcking of vacuum gas oil is shown in Figure 1.

The hydrocracking evaluation was carried out under $390{ }^{\circ} \mathrm{C}$, a total pressure of $5.5 \mathrm{MPa}$, a weight hourly space velocity (WHSV) of 1.1 $\mathrm{h}^{-1}$, and a volumetric hydrogen/oil ratio of 1030 (N lit/kg). After a stabilization period of $5 \mathrm{~h}$, reaction products were collected and analyzed. The boiling point distribution of liquid products was obtained by simulated distillation (SIMDIS, ASTM D2887). The liquid products were fractionated into naphtha $\left(90-160{ }^{\circ} \mathrm{C}\right)$, kerosene $\left(160-275^{\circ} \mathrm{C}\right)$, gas oil $\left(275-377^{\circ} \mathrm{C}\right)$ and residue product boiling above $377^{\circ} \mathrm{C}$.

The selectivity and yield of the product were obtained by following equations:

$$
\begin{aligned}
& \% \text { Selectivity } P_{i}=\frac{x_{i}(w t .) \%}{\sum x_{i}(w t .) \%} \\
& \text { Yield } P_{i}=\frac{x_{i}(w t .) \%}{\operatorname{Residue}(w t .) \% \text { Feedstock }}
\end{aligned}
$$

where, $P_{i}$ is a desired product and $x_{i}$ is a weight percent of $P_{i}$.

\section{Results and Discussion}

\subsection{Characterization of Catalysts}

The powder XRD patterns of the assynthesized beta-zeolites are presented in Figure 2. X-ray diffraction patterns of the final solids show the typical features of beta-zeolite (JCPDS No.: 47-0183). For the dried sample, the peak of $100 \%$ intensity is detected at $2 \theta=$ $22.45^{\circ}$, in agreement with Cambor et al. work [15]. Crystal diameter of the samples is calculated using Scherrer equation. The results are shown in Table 2. 
As it is shown in Table 2 the crystal sizes of the samples are less than $30 \mathrm{~nm}$. The low crystal size could be due to low crystallization temperature $140^{\circ} \mathrm{C}$ [17-20]. FE-SEM images of the as-synthesized samples are shown in Figure 3. Synthesized beta-zeolites are found to be spherical and very homogenous for all the samples prepared with different aluminum sources. Figure 3 indicates that the sample prepared by aluminum isopropylate (B3) has the lowest nanoparticle size.
The BET surface area $\left(S_{B E T}\right)$, pore volume $\left(P_{V}\right)$ and pore diameter $\left(P_{D}\right)$ of the beta-zeolite are shown in Table 2. As it is indicated in Table 2 , by decreasing crystal size of the samples the surface area of the corresponding sample is increased. In addition, a smaller crystallite size provides a higher pore volume. This result is in coincident with Modhera's report [21]; they claimed that higher pore volume and surface area of the sample with lower crystal size could be due to interparticle voids produced by aggre-

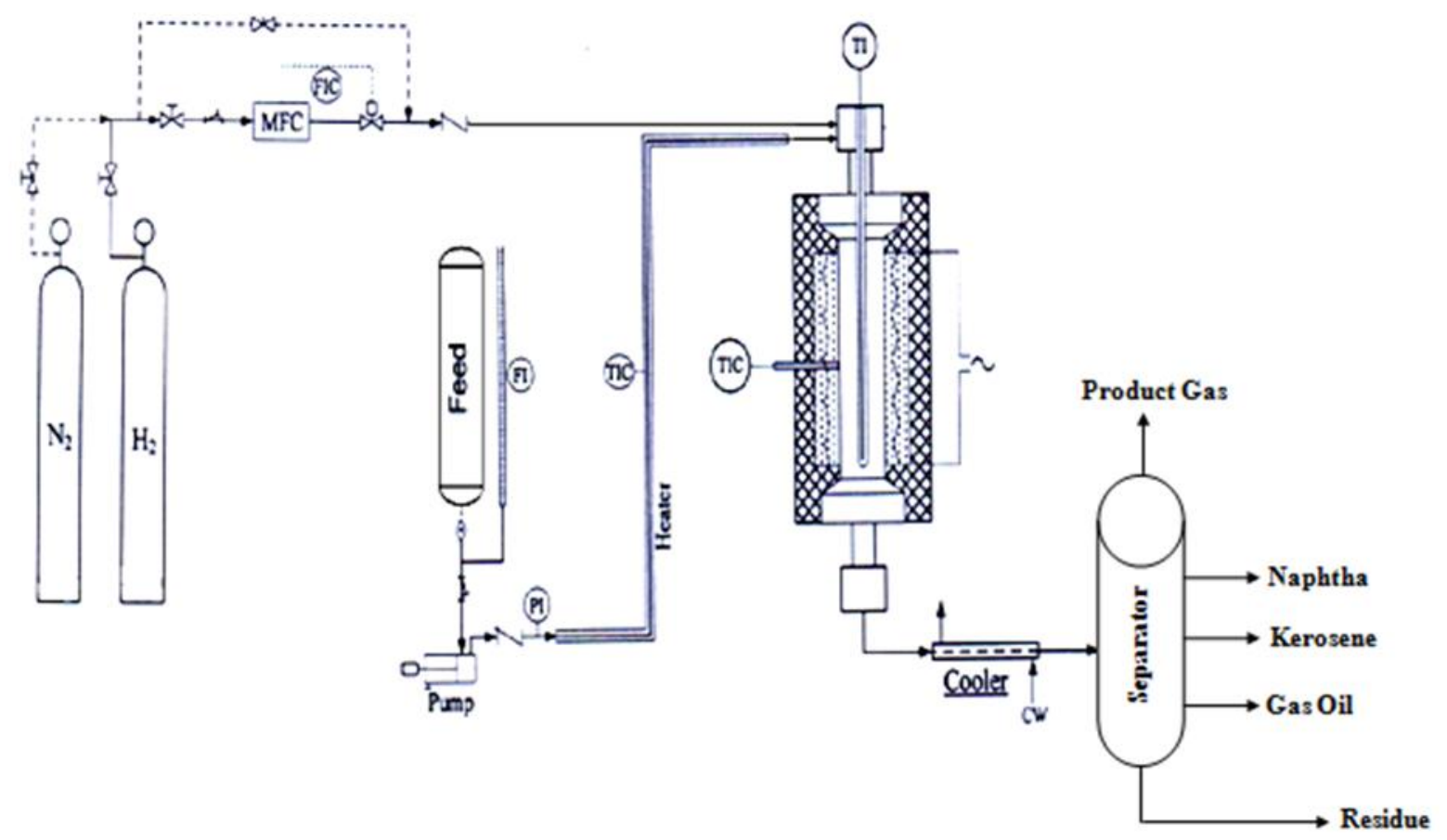

Figure 1. Schematic diagram of experimental setup for hydrocracking of vacuum gas oil
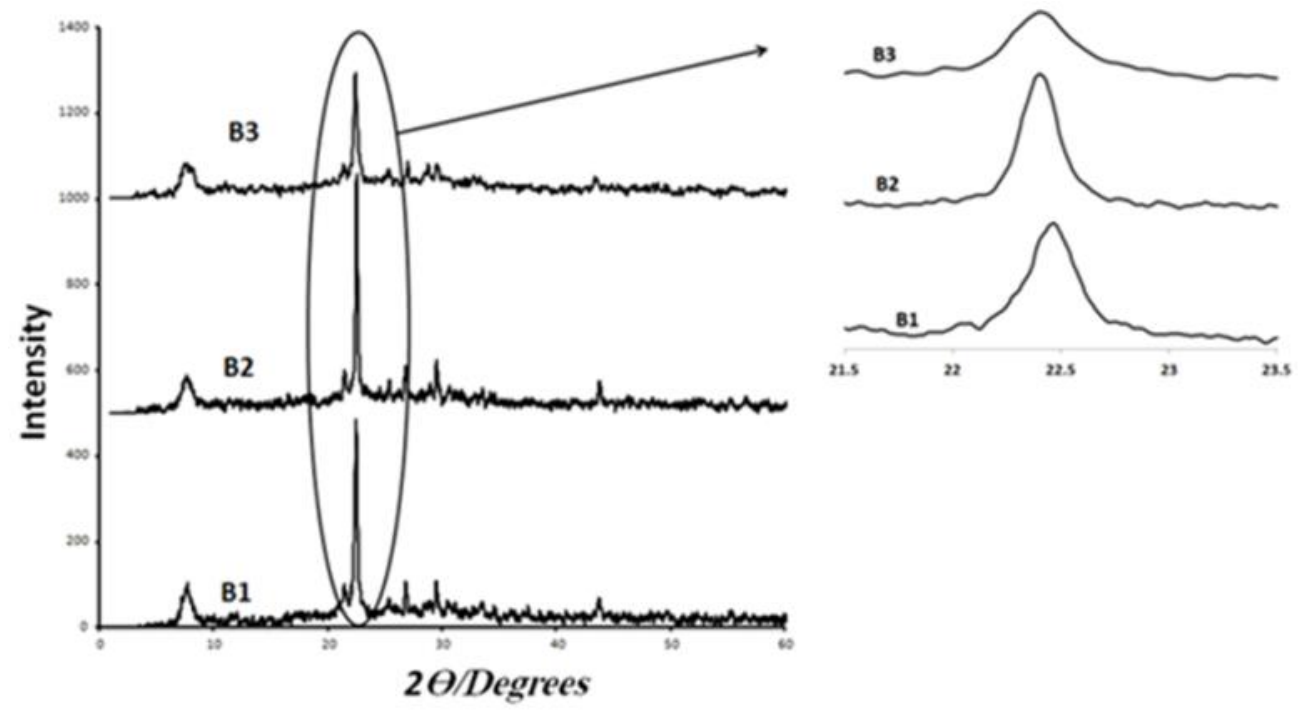

Figure 2. XRD patterns of the prepared nano beta-zeolite samples 
gation of small crystals. As it was mentioned in experimental section, in preparation of B3 sample with the lowest crystal size, aluminum isopropylate was used as a source of aluminum. In comparison with the other aluminum sources aluminum isopropylate by formation of isopropanol during hydrolysis may be inhibiting the growth of nanocrystalline beta, which leads to smaller crystal size [29].

As synthesized nano beta-zeolites samples utilized in Ni-Mo/beta-zeolite catalysts. Adsorption-desorption isotherms of the catalysts are shown in Figure 4. As shown in Figure 4, all these isotherms are similar to isotherm IV that means all the samples are mesopore compounds. The pore size distribution of the catalysts is shown that these three catalysts have mostly a pore size of $<10 \mathrm{~nm}$. Hysteresis area for $\mathrm{Ni}-\mathrm{Mo} / \mathrm{B} 3$ is small than the others. In $\mathrm{Ni}$ $\mathrm{Mo} / \mathrm{B} 1$ and Ni-Mo/B2 pore diameter distribution has two peaks (one peak around $2 \mathrm{~nm}$ ) that

Table 2. Physical properties of as-prepared beta-zeolite samples

\begin{tabular}{ccccc}
\hline $\begin{array}{c}\text { Sam- } \\
\text { ples }\end{array}$ & $\begin{array}{c}S_{B E T^{*}} \\
\left(\mathrm{~m}^{2} \mathrm{~g}^{-1}\right)\end{array}$ & $\begin{array}{c}P_{V}^{* * *} \\
\left(\mathrm{~cm}^{3} \mathrm{~g}^{-1}\right)\end{array}$ & $\begin{array}{c}P_{D}^{* * *} \\
(\mathrm{~nm})\end{array}$ & $\begin{array}{c}\text { Crystal } \\
\text { size }(\mathrm{nm})\end{array}$ \\
\hline B1 & 420 & 0.26 & 2.5 & 30 \\
B2 & 497 & 0.25 & 2.0 & 26 \\
B3 & 639 & 0.42 & 2.4 & 19 \\
\hline
\end{tabular}

${ }^{*}$ Sвет: Surface area; ${ }^{* *} \mathrm{P}_{\mathrm{V}}$ : Pore volume; ${ }^{* *} \mathrm{P}_{\mathrm{D}}$ : Pore diameter

Table 3. Physical properties of catalysts

\begin{tabular}{cccc}
\hline Samples & $\begin{array}{c}\mathrm{S}_{\mathrm{BET}} \\
\left(\mathrm{m}^{2} \mathrm{~g}^{-1}\right)\end{array}$ & $\begin{array}{c}\mathrm{P}_{\mathrm{V}} \\
\left(\mathrm{cm}^{3} \mathrm{~g}^{-1}\right)\end{array}$ & $\mathrm{P}_{\mathrm{D}}(\mathrm{nm})$ \\
\hline Ni-Mo/B1 & 134 & 0.20 & 6.1 \\
Ni-Mo/B2 & 133 & 0.27 & 8.1 \\
Ni-Mo/B3 & 213 & 0.36 & 6.8 \\
\hline
\end{tabular}

attributed to zeolite and amorphous silicaalumina, and could be made trouble about entry of the feedstock into the pore and exit of product from the pore. Moreover, for a microporous catalyst the metal sets down have been occurred nearby to the external surface of the catalyst, causing to poisoning the pore mouth [30]. The widest pore size distribution of the Ni-Mo/B3 could help hydrocracking reactions because wide pores avoid diffusion and plugging problems. So, these results indicate that using aluminum isopropylate in preparing the zeolite can lead to achieving the proper properties of the products.

Physical properties of catalysts are shown in Table 3. It can be inferred from the Table 3 that after combination of nano beta-zeolite with amorphous silica-alumina and impregnation with $\mathrm{Ni}$ and Mo, surface area was decreased. However, the pore diameter of the samples have been increased which can be due to addition of silica-alumina with large pore diameter to the zeolites. Moreover, impregnation the support with Ni-Mo has blocked the micropores. In general, Ni-Mo/B3 catalyst has biggest surface area $\left(213 \mathrm{~m}^{2} / \mathrm{g}\right)$ and pore volume $\left(0.36 \mathrm{~cm}^{3} / \mathrm{g}\right)$ that is proper to improve the hydrocracking of bulky molecules.

Figure 5 presents the TPR profiles of the samples and Table 4 summarizes the corresponding hydrogen consumptions. The TPR profiles in Figure 5 shows different reduction steps. The first one is a peak placed at about $490-520{ }^{\circ} \mathrm{C}$ and can be allocated to polymeric octahedral Mo species on the zeolite surface, because of its low reduction temperature located outside the zeolite cavities [22]. The second one at about $690-770{ }^{\circ} \mathrm{C}$ could be related to tetrahedrally coordinated Mo species in the zeolite cavities [23]. The reduction observed at about $610-640{ }^{\circ} \mathrm{C}$ could be assigned to the reduction of octahedrally coordinated $\mathrm{Ni}^{2+}$ species
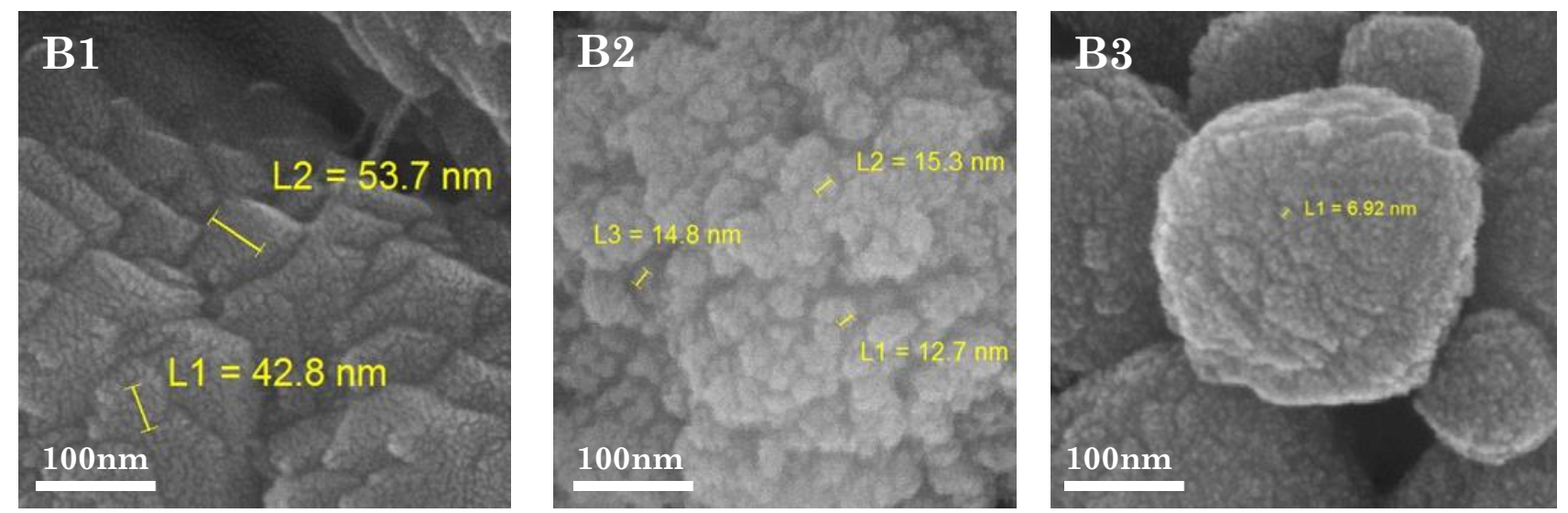

Figure 3. FE-SEM images of as-synthesized samples 

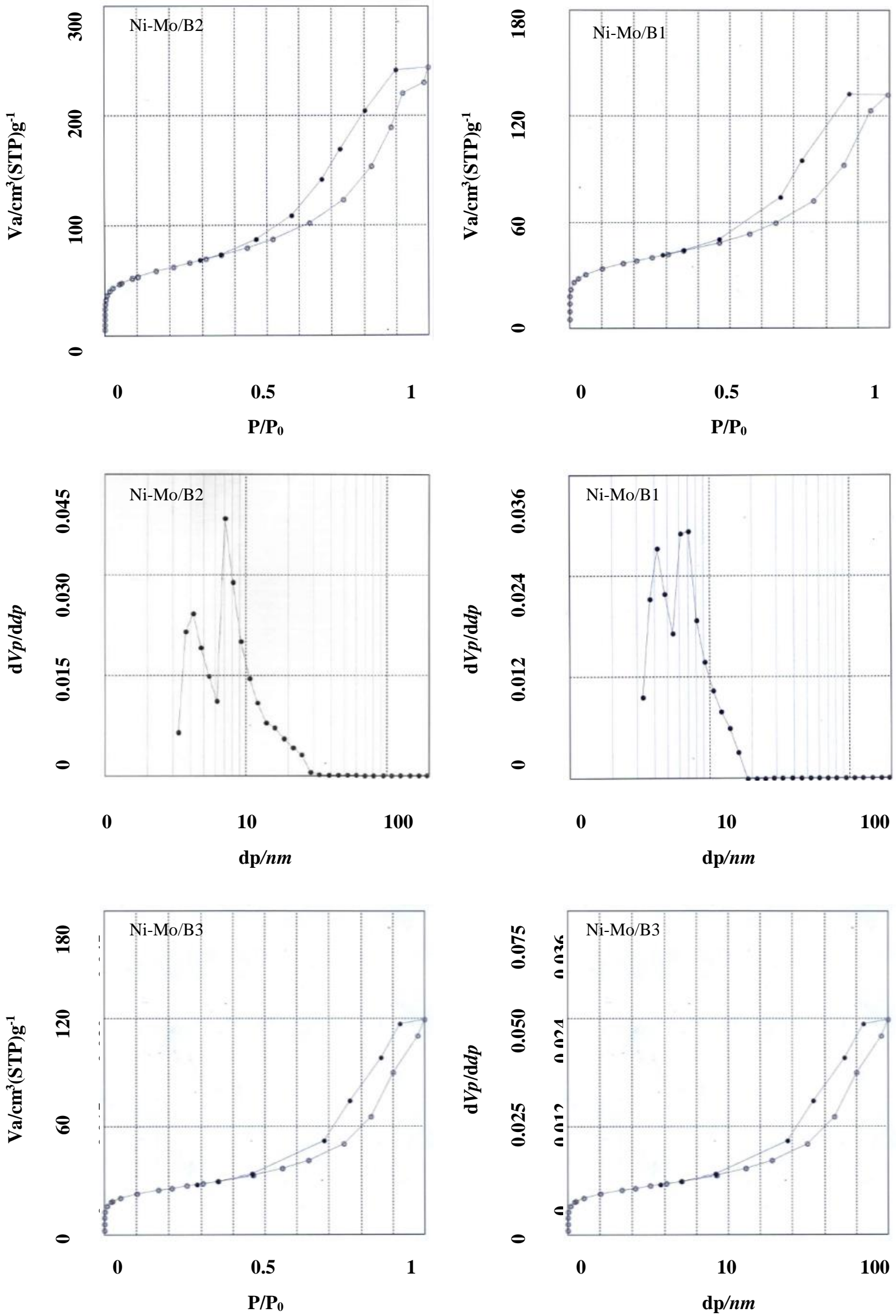

Figure 4. Adsorption-Desorption isotherms and pore size distribution of Ni-Mo/nano beta-zeolite catalysts 
on the support surface [27]. However, a small shoulder at about $440{ }^{\circ} \mathrm{C}$ for $\mathrm{Ni}-\mathrm{Mo} / \mathrm{B} 1$ and $\mathrm{Ni}-\mathrm{Mo} / \mathrm{B} 2$ samples can be assigned to the reduction of bulk $\mathrm{NiO}$ which is impregnated separately on beta-zeolite [1]. According to Figure 5, $\mathrm{Ni}-\mathrm{Mo} / \mathrm{B} 2$ catalyst reduce in lower temperature than other catalysts, proved that in this catalyst, there is weak interaction between the support and metal compounds. It can be noticed from Table 4 that the $\mathrm{H}_{2}$ consumption per gram of catalyst in Ni-Mo/B3 catalyst is higher than the other samples that indicate higher reducibility of the catalyst. Reduction of bulk $\mathrm{NiO}$ is not observed for Ni-Mo/B3 sample. The reason is that $\mathrm{NiO}$ has interaction with the high surface of the beta-zeolite prepared by aluminum isopropylate. This means that high porosity created by aluminum isopropylate leads to proper dispersion of $\mathrm{NiO}$ and lack of bulk $\mathrm{NiO}$ on the surface of the catalyst.

$\mathrm{NH}_{3}$-TPD test was used for the characterization of the catalysts in terms of the nature and number of surface acid sites. Figure 6 displays the $\mathrm{NH}_{3}$-TPD profiles for Ni-Mo/beta-zeolites catalysts that synthesized by different aluminum sources. To compare the acidity distribution among the catalysts, the weak, medium, and strong acidities are assigned to the peak

Table 4. $\mathrm{H}_{2}$ and $\mathrm{NH}_{3}$ consumption (mmol/g) of nano beta-zeolite supported Ni-Mo catalysts

\begin{tabular}{ccc}
\hline Samples & $\begin{array}{c}\mathrm{H}_{2} \text { consump- } \\
\text { tion (mmol of } \\
\mathrm{H}_{2} / \text { g cat) }\end{array}$ & $\begin{array}{c}\mathrm{NH}_{3} \text { consumption } \\
\text { (mmol of } \mathrm{NH}_{3} / \text { g cat) } \\
\text { (Total Acidity) }\end{array}$ \\
\hline $\mathrm{Ni}-\mathrm{Mo} / \mathrm{B} 1$ & 2.35 & 1.51 \\
$\mathrm{Ni}-\mathrm{Mo} / \mathrm{B} 2$ & 1.47 & 1.47 \\
$\mathrm{Ni}-\mathrm{Mo} / \mathrm{B} 3$ & 2.43 & 1.66 \\
\hline
\end{tabular}

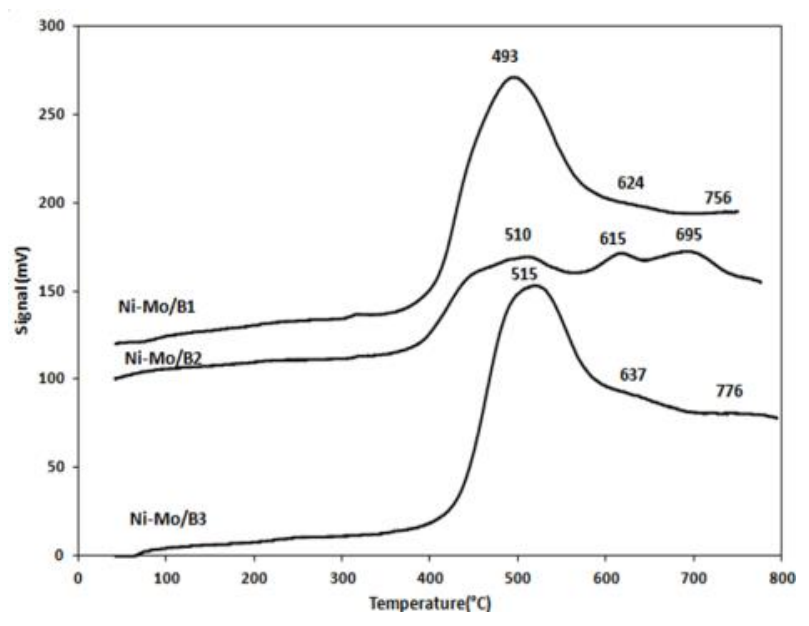

Figure 5. TPR patterns of Ni-Mo/nano betazeolite samples areas of $\mathrm{NH}_{3}$-TPD curves below $350{ }^{\circ} \mathrm{C}$, at 350 $500{ }^{\circ} \mathrm{C}$, and above $500{ }^{\circ} \mathrm{C}$, respectively $[24,25]$. However, TPD profile of Ni-Mo/B3 indicates that the strong acidity of this catalyst is lower than the others, while medium acidity of this catalyst is more than the other ones. In general the results show that acidity in B3 zeolite is milder than the other zeolites just like an amorphous silica-alumina that has weak and medium acid sites [32]. Occeli et al. claimed that by using aluminum isopropylate is used as a source of aluminum, hydrolysis and condensation reactions of the alkoxide with the silicate species in the hydrogel could led to a distribution of acid site strengths similar to those in amorphous silica-alumina [33]. As shown in Figure 6, all of the catalysts have two distinct peaks assigned to weak (below $350{ }^{\circ} \mathrm{C}$ ) and strong acidity (above $500{ }^{\circ} \mathrm{C}$ ) and weak shoulder in the region of medium acidity (350-500 $\left.{ }^{\circ} \mathrm{C}\right)$. The strong acidity of Ni-Mo/B3 is appeared around $500-600{ }^{\circ} \mathrm{C}$ which is similar to amorphous silica-alumina while the strong acidity of the others is appeared around $600-700{ }^{\circ} \mathrm{C}$ which is similar to zeolite behavior.

According to this fact that the amount of ammonia desorbed in the high temperature region indicates strong zeolitic acid sites, it could be concluded that the concentration of strong acid sites is responsible for zeolite acidity in hydrocracking reaction [28]. Higher strong acid sites may cause higher cracking and more low products that undesirable for this work. Table 3 show the ammonia consumption of the prepared catalysts. This table indicates that total acid sites for Ni-Mo/B3 catalyst are higher than the other samples that could be expected by higher surface area, because high external surface area increases number of acid sites.

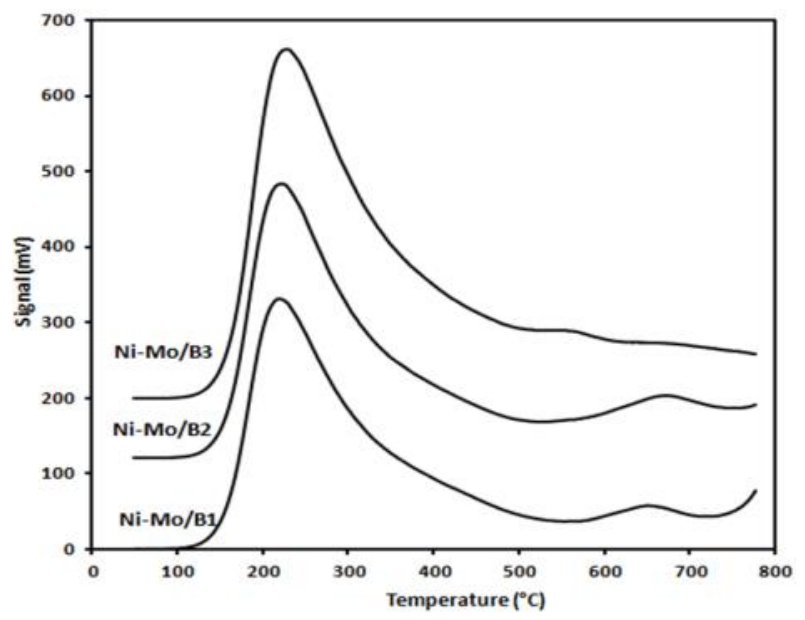

Figure 6. TPD profiles of $\mathrm{Ni}-\mathrm{Mo} /$ nano-beta zeolite samples 
3.2 Hydrocracking of Vaccuum Gas Oil using Nano Beta-zeolites Containing Silica-Alumina

Figure 7 and Table 5 show the results obtained from hydrocracking of vaccuum gas oil using Ni-Mo/beta-zeolite catalysts. As shown in Table 5 and Figure 7, Ni-Mo/B3 catalyst has higher selectivity to gas oil, desirable product, more activity and higher yield than the other catalysts, while the ability of cracking and hydrogen transfer over the surface of Ni-Mo/B1 are lower than other samples.

It is clarified that zeolite has higher catalytic performance (activity and selectivity) for gasoline than amorphous silica-alumina in the catalytic cracking of heavy feedstocks [26]. Ordinarily, the hydrocracking activity is related to the number of acid sites. The higher yield of the catalyst with a smaller crystallite size betazeolite attributed to the acidity of beta-zeolite. This result can be ascribed to a greater amount of available acid sites because of higher surface area and more mesopores of a smaller crystallite size zeolite [31]. Selectivity to gas oil decrease from 71.9 to 50.3 (\%), while the selectivity to naphtha increases from 1.6 to 3.5 (\%) as the crystallite size of beta-zeolite increases from about 19 to $30(\mathrm{~nm})$, surface area decrease from 213 to $133\left(\mathrm{~m}^{2} / \mathrm{g}\right)$ and number of acid sites decrease from 1.66 to 1.47 ( $\left.\mathrm{mmol}_{\text {of }} \mathrm{NH}_{3} / \mathrm{g}\right)$.

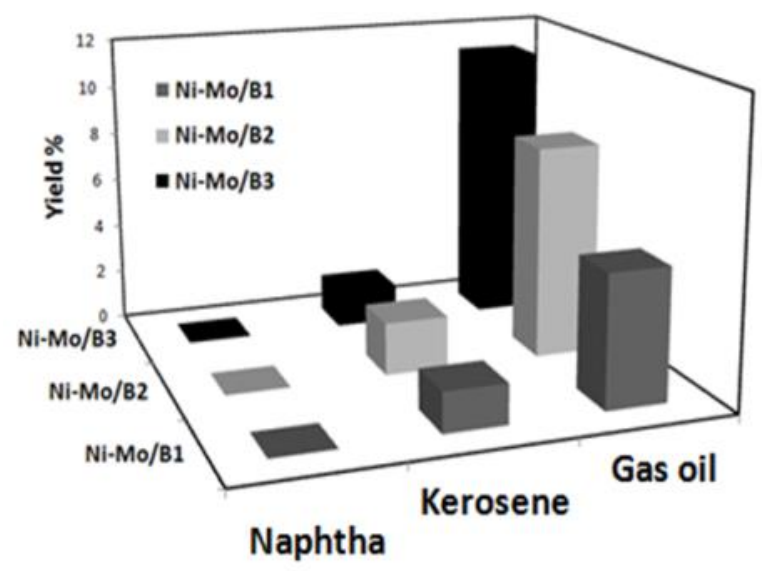

Figure 7. Yield of Ni-Mo/nano-beta zeolite samples

Table 5. Selectivity of different catalyst with hydrocracking of vacuum gas oil

\begin{tabular}{ccccc}
\hline \multirow{2}{*}{ Samples } & \multicolumn{4}{c}{ Selectivity (\%) } \\
\cline { 2 - 5 } & Gas & Naphtha & Kerosene & Gas Oil \\
\hline Ni-Mo/B1 & 1.1 & 3.1 & 15.3 & 50.3 \\
Ni-Mo/B2 & 0.7 & 3.5 & 14.6 & 60.9 \\
Ni-Mo/B3 & 0 & 1.6 & 10.1 & 71.9 \\
\hline
\end{tabular}

These results indicate that the catalyst with a smaller crystallite size beta-zeolite exhibits higher gas oil selectivity. Because of the primary cracking product easily disperses out from the short pore channel of a smaller crystallite size beta-zeolite. Thus, the undesirable secondary cracking may be impossible to take place. When the crystal size of beta-zeolite was smaller than $50 \mathrm{~nm}$, the diffusion limitations became insignificant. The greatly increased external surface area and high fraction of acid sites provide the active sites, for the molecules that are too big to enter the pores of zeolites [31]. It is expected that decrease in crystal size brings about increase in the ratio of external atoms to the internal ones, a large external surface, a high diffusive rate and many exposed acid sites [26]. According to this expectation, Ni-Mo/B3 catalyst that prepared by using aluminum isopropylate may has higher activity than other because the crystal sizes of B3 is much smaller than B1 and B2.

\section{Conclusions}

Nano beta-zeolites synthesized with various sources of aluminum (sodium aluminate, aluminum sulfate and aluminum isopropylate) were used as catalysts for mild hydrocracking of vacuum gas oil in a fixed bed continuous reactor. The results indicate that source of aluminum had a drastic effect on crystal size and morphology of the samples. It was found that, the zeolite prepared by aluminum isopropylate had the finest crystal size causes highest surface area. Subsequently, the highest surface area in Ni-Mo/beta-zeolite catalyst, the highest total acid site and reducibility of metal on support surface. Hydrocracking activity on the catalyst with a smaller crystallite size of betazeolite was higher than the others. In conclusion, beta-zeolite that prepared by aluminum isopropylate possessed the highest selectivity to gas oil.

\section{References}

[1] Hassan, A., Ahmed, S., Ali, M.A., Hamid, H., Inui, T. (2001). A Comparison between $B$ and USY Zeolite Based Hydrocracking Catalysts. Applied Catalysis A, 220: 59-68.

[2] Landau, M.V., Vradman, L., Valtchev, V., Lezervant, J., Liubich, E., Talianker, M. (2003). Hydrocracking of Heavy Vacuum Gas Oil with a Pt/H-beta- $\mathrm{Al}_{2} \mathrm{O}_{3}$ Catalyst: Effect of Zeolite Crystal Size in the Nanoscale Range. Industrial \& Engineering Chemistry Research, 42: 2773-2782. 
[3] Cui, Q., Zhou, Y., Wei, Q., Tao, X., Yu, G., Wang, Y., Yang, J. (2012). Role of the Zeolite Crystallite Size on Hydrocracking of Vacuum Gas Oil over NiW/Y-ASA Catalysts. Energy \& Fuels, 26: 4664-4670.

[4] Cui, Q., Zhou, Y., Wei, Q., Yu, G., Zhu, L. (2013). Performance of Zr- and P-Modified USY-based Catalyst in Hydrocracking of Vacuum Gas Oil. Fuel Processing Technology, 106: 439-446.

[5] Henry, R., Tayakout-Fayolle, M., Afanasiev, P., Lorentz, C., Lapisardi, G., Pirngruber, G. (2014). Vacuum Gas Oil Hydrocracking Performance of Bifunctional $\mathrm{Mo} / \mathrm{Y}$ Zeolite Catalysts in a Semi-batch Reactor. Catalysis Today, 220: 159-167.

[6] Kumaran, G., Garg, Muthu., Kumar, Shelu., Viswanatham, Manoj., Gupta, N., Sharma, J.K., Dhar, L.D., Murali, G. (2006). Origin of Hydrocracking Functionality in B-ZeoliteSupported Tungsten Catalysts. Energy \& Fuels, 20: 2308-2313.

[7] Xu, B., Rodunno, F., Bordiga, S., Prins, R., Bokhoven, J.A. (2006). Reversibility of Structural Collapse in Zeolite Y: Alkane Cracking and Characterization. Journal of Catalysis, 241: 66-73.

[8] Soualah, A., Lemberton, J.L., Pinard, L., Chater, M., Magnoux, P., Moljord, K. (2008) Hydroisomerization of Long-chain-alkanes on Bifunctional Pt/Zeolite Catalysts: Effect of the Zeolite Structure on the Product Selectivity and on the Reaction Mechanism, Applied Catalysis A, 336: 23-28.

[9] Cao, F., Wu, Y., Gu, J., Wang, J. (2011). Hydrothermal Synthesis of Nanocrystalline Zeolite Beta by Acid-catalyzed Hydrolysis of Teraethylorthosilicate, Materials Chemistry and Physics, 130: 727-732.

[10] Chaikittisilp, W., Yokoi, T., Okubo, T. (2008). Crystallization Behavior of Zeolite Beta with Balanced Incorporation of Silicon and Aluminum Synthesized from Alkali Metal Cationfree Mixture. Microporous Mesoporous Materials, 116: 188-195.

[11] Sagarzazu, A., González, G. (2013). Influence of $\mathrm{TEA}_{2} \mathrm{O} / \mathrm{SiO}_{2}$ Ratio on the Polymorph Formation and Crystallization of Zeolite Beta. Materials Chemistry and Physics, 138: 640649.

[12] Zhang, H., Xie, B., Meng, X-J., Müller, U., Yilmaz, B., Feyen, Ms., Maurer, S., Gies, H., Tatsumi, T., Bao, X., Zhang, W., DeVos, D., Xiao, F-Sh. (2013). Rational Synthesis of Beta Zeolite with Improved Quality by Decreasing Crystallization Temperature in Organotemplate-free Route. Microporous Mesoporous Materials, 180: 123-129.
[13] Mintova, S., Valtchev, V., Onfroy, T., Marichal, C., Knözinger, H., Bein, T. (2006). Variation of the Si/Al Ratio in Nanosized Zeolite Beta Crystals. Microporous Mesoporous Materials, 90: 237-245.

[14] Chen, S., Li, T., Cao, G., Guan, M. (2002). US Patent 6399530.

[15] Camblor, M.A., Corma, A., Mifsud, A., PerezPariente, J., Valencia, S. (1997). Synthesis of Nanocrystalline Zeolite Beta in the Absence of Alkali Metal Cations. Studies in Surface Science and Catalysis, 105: 341-348.

[16] Lakshmi Kantam, Rao, M., Bhavnari, P.C., Choudary, B.M., Koteswara Rao, K., Sreedhar, B., Iwasawa, Y., Sasaki, T. (2006). Synthesis of Nanocrystalline Zeolite Beta in Supercritical Fluids, Characterization and Catalytic Activity. Journal of Molecular Catalysis A: Chemical, 252: 76-84.

[17] Wu, Q., Wang, X., Qi, G., Guo, Q., Pan, Sh., Meng, X., Xu, J., Deng, F., Fan, F., Feng, Zh., Li, C., Maurer, S., Muller, U., Xiao, F-Sh. (2014). Sustainable Synthesis of Zeolites without Addition of both Organotemplates and Solvents. Journal of American Chemical Society, 136: 4019-4025.

[18] Kore, R., Satpati, B., Srivastava, R. (2011). Synthesis of Dicationic Ionic Liquids and their Application in the Preparation of Hierarchical Zeolite Beta. Chemistry A European Journal, 17: 14360-14365.

[19] Kim, D.S., Chang, J-S., Hwang, J-S., Park, SE., Kim, J.M. (2004). Synthesis of Zeolite Beta in Fluoride Media under Microwave Irradiation. Microporous Mesoporous Materials, 68: 77-82.

[20] Zhang, J., Cao, P., Yan, H., Wu, Zh., Dou, T. (2016). Synthesis of Hierarchical Zeolite Beta with Low Organic Template Content via the Steam-assisted Conversion Method. Chemical Engineering Journal, 291: 82-93.

[21] Modhera, B., Chakraborty, M., Parikh, P.A., Jasra, R.V. (2009). Synthesis of Nano-crystalline Zeolite B: Effects of Crystallization Parameters. Crystal Research and Technology, 44: 379-385.

[22] Qu, L., Zhang, W., Kooyman, P.J., Prins. R. (2003). MAS NMR, TPR, and TEM Studies of the Interaction of NiMo with Alumina and Silica-Alumina Supports. Journal of Catalysis, 215: 7-13.

[23] Al-Dalama, Kh., Stanislaus, A. (2011). Temperature Programmed Reduction of $\mathrm{SiO}_{2}$ $\mathrm{Al}_{2} \mathrm{O}_{3}$ Supported Ni, Mo and NiMo Catalysts Prepared with EDTA. Thermochimia Acta, 520: 67-74. 
[24] Jiang, J., Dong, Zh., Chen, H., Sun, J., Yang, Ch., Cao, F. (2013). The Effect of Additional Zeolites in Amorphous Silica-Alumina Supports on Hydrocracking of Semirefined Paraffinic Wax. Energy \& Fuels, 27: 1035-1039.

[25] Ding, L. Zheng, Y., Zhang, Z., Ring, Z., Chen, J. (2006). Hydrotreating of Light Cycled Oil using $\mathrm{WNi} / \mathrm{Al}_{2} \mathrm{O}_{3}$ Catalysts Containing Zeolite Beta and/or Chemically Treated Zeolite Y. Journal of Catalysis, 241: 435-445.

[26] Meng, Q., Liu, B., Piao, J., Liu, Q. (2012). Synthesis of the Composite Material Y/ASA and Its Catalytic Performance for the Cracking of n-Decane. Journal of Catalysis, 290: 5564 .

[27] Solı's, D., Agudo, A.L., Ramı́rez, J., Klimova, T. (2006). Hydrodesulfurization of Hindered Dibenzothiophenes on Bifunctional NiMo Catalysts Supported on Zeolite-Alumina Composites. Catalysis Today, 116: 469-477.

[28] Manrique, C., Guzman, A., Perez- Pariente, J., Márquez-Álvarez, C., Echavarría. A. (2016). Effect of Synthesis Conditions on Zeolite Beta Properties and Its Performance in Vacuum Gas Oil Hydrocracking Activity. Microporous Mesoporous Materials, 234: 347360 .
[29] Zhang, X., Tang, D., Jiang, G. (2013). Synthesis of Zeolite NaA at Room Temperature: The Effect of Synthesis Parameters on Crystal Size and Its Size Distribution. Advanced Powder Technology, 24: 689-696.

[30] Ancheyta, J., Speight, J.G. (2007). Hydroprocessing of Heavy Oils and Residual, CRC Press, pp. 146.

[31] Ding, L., Zheng, Y., Yang, H., Parviz, R. (2009). LCO Hydrotreating with Mo-Ni and W-Ni Supported on Nano- and Micro-sized Zeolite Beta. Applied Catalysis A, 353: 17-23.

[32] Leydier, F., Chizallet, C., Chaumonnot, A., Digne, M., Soyer, E., Quoineaud, A-A., Costa, D., Raybaud, P. (2011). Brønsted Acidity of Amorphous Silica-Alumina: The Molecular Rules of Proton Transfer. Journal of Catalysis, 284: 215-229.

[33] Occelli, M.L., Biz, S., Auroux, A., Ray, G.J. (1998). Effects of the Nature of the Aluminum Source on the Acidic Properties of Some Mesostructured Materials. Microporous Mesoporous Materials, 26: 193-213. 